\title{
EL OTRO Y SU DESPLAZAMIENTO EN LA ÚLTIMA LITERATURA DE VIAJE
}

\author{
PATRICIA AlMARCEGUi \\ Universidad de Zaragoza
}

\section{RESUMEN}

Este artículo pretende avanzar en el estudio de la representación del Otro en la literatura de viaje. Para ello, presenta una serie de ejemplos puntuales que recogen algunos de los momentos de la evolución del término heredado de la antropología. Para, finalmente analizar la última literatura, que muestra el cambio de significado o desplazamiento que ha sufrido dicha categoría.

Palabras clave: Otro, lugar, desplazamiento.

\section{THE OTHER AND ITS DISPLACEMENT IN THE LATEST TRAVEL LITERATURE}

\begin{abstract}
This article pretends to advance in the study of the representation of the other in the travel literature. For this, presents a series of punctual examples that collect some of the moments of the evolution of the term inherited of the anthropology. For finally analyze the last literature, that shows the change of meaning or displacement.
\end{abstract}

Key Words: Other, place, displacement.

Uno de los elementos más destacados dentro de la poética del viaje es el encuentro con el Otro. Una de las causas por las que el itinerario hace concebir de manera diferente. Viajero, habitante y lugar se encuentran y este choque descubrimiento actúa como un elemento funcional. En las últimas décadas, el análisis del Otro ha sido objeto de amplias investigaciones. En estas páginas, lo identifico a partir de los presupuestos defendidos por G. Simmel ${ }^{1}$, quien define la sociedad a partir de lo que se encuentra fuera de ella y le resulta extraño. Y a partir de la definición del antropólogo, M. Augè, que arranca en los apuntes sociológicos anteriores: el hombre

\footnotetext{
${ }^{1}$ SIMMEL, George. El individuo y la sociedad: ensayos de crítica de la cultura. Madrid: Península, 2001, p. 344.
} 
se realiza en la dimensión social y forma un solo individual y cultural con el Otro. La cultura es un diálogo creativo abierto y cerrado de uno y del Otro $^{2}$. No hay nada del Otro en el sí mismo que no se entronque con una autorreflexión, por lo que la alteridad, es decir, la relación con él, es empírica pero también imaginaria ${ }^{3}$. Por esa razón, el Otro es el lugar del temor, del deseo, de la fascinación, de lo inconcebible, de la diferencia, del contraste, de la lejanía, pero también de sus ambivalentes, es decir, de la coincidencia, del reconocimiento, de la comparación, de la proximidad... Una hermenéutica del mismo implica la mediación de dos esferas diferentes en las que lo propio y lo extraño aparecen como conceptos relacionados entre sí. No se excluyen, sino que se mueven en la lógica del tránsito, no se mezclan sino que se solapan y se deslizan. Se trataría de encontrar y enfrentarse a ese tercer elemento que hace que un determinado extrañamiento se muestre como extraño. O lo que C. Lévi-Strauss cita como punto de partida de la filosofía social: el extrañamiento o el rodeo a través de lo extraño que nunca puede ser remitido completamente a lo propio ${ }^{4}$. El yo debería permanecer como Otro. Su mirada complementa el carácter fragmentario del viajero y lo convierte en algo que ni es ni será nunca pura ni enteramente. Solo el extrañamiento frente a uno mismo hace posible que lo extraño aparezca como tal ${ }^{5}$.

La cuestión es cómo el viajero maneja ese extrañamiento, que ni es absoluto, ni identificable con un solo registro, y cómo se perfila una teoría de la experiencia de la alteridad durante el viaje. El itinerario es uno de los elementos más significativos para encontrarse con el Otro. Pues el lugar, el movimiento y el desplazamiento que lo determinan ponen en contacto y aceleran las categorías que definen la alteridad, principalmente: un lenguaje ininteligible, un comportamiento inusual y una procedencia desconocida.

La identidad del viajero se ve alterada por el encuentro con él, en la mayor parte de los casos, sufre una metamorfosis parcial o total. La relación se establece desde el viajero hacia el Otro, quien es leído a partir del observador. Se podría decir que no hay encuentro fecundo si no hay afirmación de identidad: se viaja para reencontrarse. Y, gracias a esta percepción del «yo en el viaje», el observador sufre, más que un encuentro con la alteridad, una serie de alteraciones en su identidad. Asimismo, el desplazamiento implica un retorno, el del viajero que se interpreta a sí mismo y reconoce el mundo a partir del conocimiento que le devuelve el encuentro, el cual se haya ligado a una situación compartida. No hay significado

\footnotetext{
${ }^{2}$ AUGÈ, Marc. El sentido de los otros: actualidad de la antropología. Barcelona: Paidós, 1996, p.11.

${ }^{3}$ LACAN, Jacques. Seminario XXI. Barcelona: Paidós, 1999, p. 114.

${ }^{4}$ LEVI-STRAUS, Claude. Antropología estructural. Barcelona: Paidós, 1987, p. 234.

${ }^{5}$ RICOEUR, Paul. Sí mismo como Otro. Madrid: Siglo XXI, 1996, p. 22.
} 
sin interlocución o, lo que es lo mismo, la mitad de la palabra le pertenece al Otro pues el observador depende de él. Más adelante, la crisis de la unidad llevará a descubrir el yo del viajero en una variedad y heterogeneidad de formas y significados en los destinos, y la riqueza del exterior pasará a proyectarse en su interior.

Una de las primeras muestras de la poética de la alteridad es la representación que hace Herodoto en las Historias de persas, escitas y egipcios. En primero lugar, el historiador afirma una diferencia para, en segundo, traducirla o aprehenderla a través de un esquema de inversión, como ocurre, por ejemplo, con la descripción que hacen los griegos de los escitas y los egipcios:

Decir el Otro, es situarlo como diferente, es decir que existen dos términos $a$ y $b$ y que $a$ no es $b$, o sea que existen griegos y no griegos. Pero la diferencia no es interesante hasta el momento en que $a$ y $b$ entran en un mismo sistema: no tienen más que una pura y simple coincidencia [...]. A partir de la relación fundamental que se erige entre dos semejanzas, la diferencia significativa puede desarrollar una retórica de la alteridad ${ }^{6}$.

De este modo, se organizan unos mecanismos que dan lugar a una estructura de la representación formada por tres elementos principales. La oposición del viajero frente al Otro, un ejercicio que le obliga a identificar los elementos con los que se define para situarlo como si fuera un obstáculo. La negación, otro mecanismo de oposición con el que, en vez de situarse frente a él, se enfrenta a él y lo interpreta a partir de sus carencias o lo que cree que le falta. Y la inversión, que le permite establecerse como un igual para más adelante realizar un trueque de las singularidades del Otro por las suyas, por ejemplo, a partir de las diferencias ideológicas y lingüísticas. Los tres casos muestran la necesidad de describir el no sentido entre el viajero y el Otro. Así la alteridad se manifiesta a golpe de contraste y en un juego de analogías y confrontaciones entre tipos y costumbres. Por eso, el Otro se suele describir a partir de elementos reconocibles, como la higiene, los alimentos, la arquitectura, la religión y el clima. En el caso de Los viajes de Marco Polo, así como en las obras de los viajeros medievales como Montecorvino, Pian de Cárpine y Rubruc, la alteridad pierde sus contornos. El Otro, que debería de corresponder a los mongoles, quienes han conquistado buena parte del mundo, se muestra en una relación de semejanza y acompañamiento que evoluciona desde el desconocimiento al conocimiento. Lo que se consigue gracias a la labor de los viajeros, quienes tienen como objetivo describir las costumbres y los modos de los herederos de Gengis Khan precisamente para aliarse con los mismos contra el gran Otro, ausente muchas veces de las obras, pero siempre pre-

\footnotetext{
${ }^{6}$ Cf. HARTOG, François. Le miroir d'Hérodote. París: Gallimard, 1980, pp. 331 y 332.
} 
sente en sus imaginarios, el Islam y sus fieles. En estas circunstancias, para vencer al Otro, la mejor forma es conocerlo.

Un caso de gran interés es el de los viajes de Vasco de Gama a la costa de Angola y Mozambique de camino hacia la India. No existe un argumento más significativo de cómo la ausencia de semejanzas y referentes entre los portugueses y el Otro provoca una historia de desencuentros. Sin conocer ni compartir ningún tipo de código, lo que en principio debería de ser un intercambio comercial (sobre el que, por cierto, los habitantes no demuestran tener mucho interés) deriva en una tensión y desconfianza que da lugar a varias muertes. La alteridad más absoluta provoca miedo y el pavor se combate con la violencia. Como norma general, Vasco de Gama espera a que se le acerquen las embarcaciones de los nativos, toma rehenes antes de pisar tierra y, rara vez, junto con sus capitanes, abandona los barcos. Sorprende además que los episodios se sucedan en un lugar «en medio de», ni en las naves portuguesas ni en las tierras africanas, sino en las barcas que unos y otros envían como preludio introductorio antes de conocerse. Allí los referentes culturales y espaciales están ausentes y por lo tanto no parecen proteger a los portugueses. El viaje por África define la conducta posterior de Vasco de Gama en la India, llena de suspicacias y generador de las mismas. Al mismo tiempo, cuando desde la costa o la tierra vislumbra las siluetas de las gopuram o torres de los templos hindúes, da por hecho que pertenecen a la fe musulmana, pues es su principal referente de alteridad. Las descripciones se integran en los dos mundos conocidos y se reducen únicamente a ellos: el cristiano y el musulmán.

Los casos más significativos de proyección de uno sobre el Otro y, por lo tanto, de la posterior lectura de los viajeros como conocimiento y ejercicio autorreflexivo, son los itinerarios científicos ilustrados. Las descripciones casi siempre peyorativas del Otro se convierten en una auténtica crítica al país de origen. Los atributos tales como la ignorancia, el despotismo, el determinismo, la superstición, la autarquía son precisamente las críticas que los viajeros hacen a su sociedad y a su política en un ejercicio singular en el que se reflejan ellos mismos.

En la literatura posterior, se encuentran sin embargo muy pocas comparaciones. El viajero desarrolla una relación vertical que se caracteriza por la desigualdad. El Otro desaparece pues nunca puede coincidir con el deseo que el observador proyecta sobre él y la imagen que crea. La diferencia es que ahora el viajero lo sabe y reconoce que el Otro pertenece al espacio de la ausencia. Como afirma E. Delacroix:

No hay viajero que no se lance desde un principio a la estéril tarea de conjeturar en su imaginación cómo es la fisionomía de los hombres y cosas que va a buscar ${ }^{7}$.

${ }^{7}$ DELACROIX, Eugène. Souvenir du voyage au Maroc. París: Gallimard, 1999, p. 67. 
El encuentro del uno y del Otro a partir de la condición común y compartida de alteridad va a ser el origen del silencio que da lugar a la imposibilidad de su representación posterior. El viajero reconoce en lo ajeno del Otro el extrañamiento interior, se introduce en dicha realidad y se ausenta de sí mismo, como ocurre en los desplazamientos del periodo de entreguerras en el siglo XX. De nuevo, se proyecta sobre el Otro y da por hecho la forma en que este se percibe a sí mismo. El extrañamiento que siente deja de ser totalmente ajeno e invade gracias al contacto con él. El conocimiento que devuelve es, precisamente, el de la inaccesibilidad total del Otro y, por lo tanto, el de la huidiza identidad del viajero. Y este representa dicha imposibilidad afirmando su desapropiación o la dificultad de hablar de él. Algo descubierto tan recientemente que debe ser expuesto de forma repetida en la última literatura de viaje, como si a través de dicha afirmación de inaccesibilidad se hiciera accesible. Los textos de Mar negro de N. Ascherson o Entre árabes de C. Thubron dan cuenta de ello. Para el primero resulta tan difícil comprender el mundo clásico, que solo puede presentarse como un narrador informador que observa siempre desde lejos. Thubron recuerda lo difícil, casi imposible, que resulta representar el destino. El viajero se haya sometido a la velocidad de la época contemporánea que le obliga a cambiar constantemente de lugar y esa movilidad le impide describirlo:

Quería encontrar un rincón privado desde el que entender el mundo clásico como un intruso informado ${ }^{8}$.

Y puesto que el mismo viajero pertenece a una civilización cambiante, su libro refleja un gusto y una sensibilidad que también está en proceso de transición ${ }^{9}$.

En estas circunstancias, el silencio es a veces la mejor solución para dar voz al Otro. No pudiéndolo aprehender totalmente, resulta, por primera vez, mejor no hablar de o por él:

Pienso que debería decirle a Hamdani [el conductor que lleva a L. Silva en Marruecos] que no es en absoluto necesario por nuestra parte que lleve siempre el traje y la corbata. Pero se me ocurre que ni siquiera sé si esa es su manera de defenderse del calor (debajo de la camisa lleva aún una camiseta) y que también puede considerar una impertinencia que me meta en cómo debe ir vestido [...]. De modo que evito una vez más el asunto ${ }^{10}$.

El viajero es responsable de la descripción del Otro. Sabe que su escritura muestra una determinada representación, a pesar de que no lo puede aprehender. Conoce lo importante que es la segregación entre lo conocido

\footnotetext{
${ }^{8}$ ASCHERSON, Nigel. El mar negro. Barcelona: Tusquets, 2001, p. 13

9 THUBRON, Colin. Entre árabes. Barcelona: Península, 2002, p. 11.

${ }^{10}$ SILVA, Lorenzo. Del Rif al Yebala. Viaje al sueño y a la pesadilla de Marruecos. Barcelona: Destino, 2001, p. 165.
} 
y lo no conocido y la alienación respecto a él. Así justifica, razona, expone su relación pero, sobre todo, explica desde qué lugar se sitúa para describirlo:

Todos [los magrebíes] nos miran fijamente. Con esas miradas empezamos a hacernos una idea de hasta qué punto vamos a tener que estar preparados para sobrellevar el peso de nuestra diferencia ${ }^{11}$.

Otras veces, el viajero duda de cómo nombrarse a sí mismo y a sus compatriotas pues sabe que la terminología no es inocente y lo que implica usar una u otra:

Casi prefiero utilizar la palabra español en esa aceptación restringida, aunque sea inexacta (muchos magrebíes de Melilla son también españoles de pasaporte), porque la alternativa, llamar a los de origen peninsular cristianos, como hace algún folleto sobre la ciudad, me resulta anticuada y aún más impropia ${ }^{12}$.

En estas circunstancias, la certeza de que no existe una realidad única se convierte en la forma preferida de representación. Las sociedades se fragmentan en tribus e identidades. La literatura de viaje no puede aprehender el mundo en su totalidad y como imagen del desorden mundial recoge sus cambios y fragmentos. Con la desaparición de dicha certeza, se pierde también las medidas con las que se interpretan las culturas modernas. La distinción entre lo propio y extraño se vuelve borrosa; aumenta el extrañamiento interior y lo familiar se vuelve extraño. En esa indeterminación en la que resulta imposible determinar quiénes son el viajero y el Otro, aparece un desplazamiento curioso. Ya no es el consabido deslizamiento del sujeto al objeto, sino del sujeto hacia un lugar. Este se carga de afectividad y, por esa razón, hay que visitarlo, pues ofrece la posibilidad de adquirir una experiencia que parece no existir en el espacio de origen. En este sentido, el lugar deviene el Otro y el viaje, la mejor forma para llegar hasta él. Se podría decir que existe un ethos de la espacialidad; unos ámbitos que definen las afinidades y diferencias del viajero y del Otro, y que permiten transgredir los límites de ambos.

Se viaja a un espacio cuya experiencia responde al afán de preguntas característico del viajero contemporáneo. El lugar responde porque remite a una experiencia anterior que solo puede tener un reconocimiento cuando se visita. En este sentido, se viaja porque se quiere tener la experiencia del Otro y el lugar, cargado de afectividad, la devuelve. Por ejemplo, J. Campos intenta revivir a Quevedo en las tierras castellanas. El esfuerzo le lleva también a rememorar a otros personajes ilustres que nacieron el mismo día que el escritor español. Como si el lugar impulsara las analogías e hiciera brotar las experiencias de otros autores:

\footnotetext{
11 Ibidem, p. 61.

12 Ibidem, p. 25
} 
Pero sí, también a él [Quevedo] le he seguido sus huellas [...]. El 26 de septiembre de 1850 fue bautizado en la iglesia de S. Ginés. Ese mismo día Michel de Montaigne se encontraba en la lorenesa villa de Plombières [...]. Ese mismo día, Francis Drake atracaba en Plymouth después de haber dado la vuelta al mundo. Quevedo tomaba las aguas bautismales que le recibían en la santa religión; Montaigne tomaba aguas medicinales para poder orinar sin dolores; Drake tomaba tierra porque ya había dejado suficiente agua salada a sus espaldas. Un simple día sirve para relacionar las imágenes que aquellos hombres desencadenaron en sus vidas ${ }^{13}$ [la cursiva es mía].

El Otro se encuentra en el lugar al que el viajero se vincula afectivamente a través de una experiencia anterior. Así los espacios crean sus propios desarrollos y constituyen las causas de los acontecimientos que lo conforman. Imposibles estos de explicar o recorrer si no es volviendo al espacio, al tiempo, al fin y al cabo, en el que tuvieron lugar. Para aproximarse al Otro es necesario percibir lo mismo que él percibió. Tener la ilusión de que se siente lo mismo que él, de allí la carga afectiva con la que y de la que se van llenando los lugares. En ellos, el viajero establece un lazo afectivo difuso como concepto, pero vivido y concreto como experiencia personal. Una de las razones por las que muchas veces la literatura de viaje se acerca también a la testimonial, pues visitar un determinado lugar es una prueba o justificación de un hecho y experiencia anterior. Así por primera vez, los últimos títulos de la literatura de viaje (y de la literatura) solo incluyen el nombre del destino, lo que pone en evidencia la relevancia que adquiere el lugar: J. Carrión, Australia, N. Ascherson, Mar Negro... El escritor A. Colomer nos recuerda cómo los lugares mantienen las experiencias históricas que los atraviesan e incluso parecen llegar a recordarla:

El dolor de la Humanidad estará por siempre representado en el lugar físico de Auschwitz; la esperanza, en Lourdes; el perdón, en Guernika; el miedo, en Transilvania; la incertidumbre, en Chernóbil; y así un largo etcétera. No nos basta a los ciudadanos del mundo con leer un puñado de ensayos donde se detallen aquellos hechos, sino que exigimos la creación de un espacio concreto donde ubicar físicamente las pasiones del alma que nos definen como colectivo. Es decir, las emociones. Así pues, los mortales reclamamos un «geografía de las emociones» sobre la que lamentar la existencia de un lado oscuro del corazón ${ }^{14}$.

Desde el esquema de inversión característico de la poética de la alteridad, hasta la búsqueda de una percepción común entre el viajero y el Otro, pasando por la confirmación de que comparten la experiencia del extrañamiento, estas páginas muestran que las relaciones entre espacio y alteridad son hoy las más pertinentes para avanzar en las contradicciones de la modernidad y el viaje la forma de la cultura que mejor las evidencia.

\footnotetext{
${ }^{13}$ CAMPO, Jesús del. Castilla y otras islas. Barcelona: Minúscula, 2008, p. 36.

${ }^{14}$ COLOMER, Álvaro. Guardianes de la memoria. Barcelona: Mr, 2007, p. 7
} 


\section{REFERENCIAS BIBLIOGRÁFICAS}

ASCHERSON, Nigel. El mar negro. Barcelona: Tusquets, 2001.

AUGÈ, Marc. El sentido de los otros: actualidad de la antropología. Barcelona: Paidós, 1996.

CAMPO, Jesús del. Castilla y otras islas. Barcelona: Minúscula, 2008.

COLOMER, Álvaro. Guardianes de la memoria. Barcelona: Mr, 2007.

DELACROIX, Eugène. Souvenir du voyage au Maroc. París: Gallimard, 1999.

HARTOG, François. Le miroir d'Hérodote. París: Gallimard, 1980.

LACAN, Jacques. Seminario XXI. Barcelona: Paidós, 1999.

LEVI-STRAUS, Claude. Antropología estructural. Barcelona: Paidós, 1987.

RICOEUR, Paul. Sí mismo como Otro. Madrid: Siglo XXI, 1996.

SIMMEL, George. El individuo y la sociedad: ensayos de crítica de la cultura. Madrid: Península, 2001.

SILVA, Lorenzo. Del Rif al Yebala. Viaje al sueño y a la pesadilla de Marruecos. Barcelona: Destino, 2001.

THUBRON, Colin. Entre árabes. Barcelona: Península, 2002.

Fecha de recepción: 29 de mayo de 2010

Fecha de aceptación: 16 de diciembre de 2010 